\title{
Herpesvirus infection with severe lymphoid necrosis affecting a beaked whale stranded in the Canary Islands
}

\author{
Manuel Arbelo1, Eva Sierra ${ }^{1}$, Fernando Esperón ${ }^{2}$, Tatiane T. N. Watanabe ${ }^{1,3}$, \\ Edwige N. Bellière ${ }^{2}$, Antonio Espinosa de los Monteros ${ }^{1}$, Antonio Fernández ${ }^{1, *}$ \\ ${ }^{1}$ Unit of Histology and Veterinary Pathology, Institute for Animal Health, Veterinary School, \\ University of Las Palmas de Gran Canaria, Canary Islands, Spain \\ ${ }^{2}$ CISA-INIA, Carretera de Algete a El Casar, 28130 Valdeolmos, Madrid, Spain \\ ${ }^{3}$ College of Veterinary Medicine and Animal Science, São Paulo State University, Brazil
}

\begin{abstract}
This report describes the pathologic findings in a single, adult female Cuvier's beaked whale Ziphius cavirostris stranded in the Canary Islands. The study indicated that this whale died with a severe, systemic, herpesviral infection and clearly exhibited lesions different from those of the fat and gas embolic syndrome described in beaked whale mass strandings associated with sonar exposure. This is the first report of a cetacean alphaherpesvirus infection of the lymphoid system in a beaked whale.
\end{abstract}

KEY WORDS: Beaked whale $\cdot$ Herpes virus $\cdot$ Lymphoid system

Resale or republication not permitted without written consent of the publisher

\section{INTRODUCTION}

To date, 87 beaked whale stranding events were recorded along the coast of the Canary Islands, with a total of 119 individual animals of 6 species stranded: Cuvier's beaked whale Ziphius cavirostris, Gervais beaked whale Mesoplodon europaeus, Blainville's beaked whale Mesoplodon densirostris, True's beaked whale Mesoplodon mirus, Sowerby's beaked whale Mesoplodon bidens and the northern bottlenose whale Hyperodon ampullatus. Of these 119 animals, at least 86 were Cuvier's beaked whales (Martín \& Tejedor 2009). This species is sighted regularly at sea, especially off the east coast of Fuerteventura and Lanzarote (V. Martín pers. comm.) and in the waters around El Hierro island (N. Aguilar de Soto pers. comm.).

In the Canary Islands waters, 28 cetacean species have been identified of which 24 species have been found stranded. Etio-pathologically, $62.32 \%$ of the cetaceans stranded in the Canary Islands subjected to pathological studies have been diagnosed as natural (i.e. non-anthropogenic) pathological entities that in- cluded infectious diseases, neonatal pathology, intraand interspecific interactions and typical mass strandings; and $33.33 \%$ of the cases have been diagnosed as anthropogenic entities including fishing interaction (by-catch), atypical mass-stranding linked to naval exercises, ship collisions, and other anthropogenicrelated pathology (Arbelo 2007).

There are few reports of herpesviral infections in marine mammals. Most reports are morphological, where the diagnosis is based on gross pathology (Baker 1992), histopathology and immunohistochemistry (Kennedy et al. 1992) or transmission electron microscopy (TEM) (Martineau et al. 1988, Van Bressem et al. 1994). So far, no cetacean herpesviruses have been isolated with cell culture; thus, molecular diagnostic tools are essential to establish their taxonomic classification. Amplification of conserved DNA regions within the herpesvirus polymerase gene (VanDevanter et al. 1996) and terminase gene (Hargis et al. 1999) has been possible using universal PCRs. Further sequencing of the resultant amplicons has provided new reports of alphaherpesvirus in the bottlenose dolphin Tursiops 
truncatus (Blanchard et al. 2001, Manire et al. 2006, Smolarek-Benson et al. 2006), and gammaherpesvirus in bottlenose dolphin, Risso's dolphin Grampus griseus, dwarf sperm whale Kogia sima and Blainville's beaked whale Mesoplodon densirostris (Saliki et al. 2006, Smolarek-Benson et al. 2006). Using a universal nested PCR, Esperón et al. (2008) reported the first herpes simplex-like infection found in a stranded dolphin.

\section{MATERIALS AND METHODS}

On April 18, 2005, 1 female adult (555 cm long) Cuvier's beaked whale was found dead on the southern coast of Fuerteventura Island (Faro la Entallada). Necropsy was performed approximately 48 to $72 \mathrm{~h}$ post-mortem (code 3) (Fernandez 2003, Fernandez et al. 2005).

Necropsy was carried out on the beach following the protocol used previously in other cases of stranded beaked whales (Fernandez et al. 2005). Lung, heart, muscle, thoracic and abdominal lymph nodes, liver, spleen, kidney, stomach, brain and intestines were sampled for routine light microscopic examination. To search for fat emboli, formalin-fixed lung and lymph node samples were post-fixed with osmium and embedded in paraffin following the procedure indicated in Fernandez et al. (2005). Lung, liver, spleen and muscle were sampled for bacteriologic aerobic culture.

For electron-microscopy (EM), formalin-fixed samples from spleen and lymph nodes were processed for routine transmission EM. A universal nested PCR (VanDevanter et al. 1996) that amplifies a conserved region within the polymerase gene of the Herpesviridae family was used in spleen, liver, muscle and lung. To detect possible carry over contamination, 2 blank controls (water, PCR-grade) were used for each reaction, one for DNA extraction and another for PCR reaction. A positive control of a herpes simplex-like sequence found in a stranded bottlenose dolphin (Esperón et al. 2008) was also used. The amplicon was directly sequenced by triplicate. Sequenced products were compared with sequences available in Genbank using the Blast search. A neighbor-joining phylogram was made using Mega 4.0 software (see Fig. 5). Sequenced products were compared with sequences available in Genbank using the Blast search.

\section{RESULTS AND DISCUSION}

The stranded whale exhibited a relatively good body condition. The main external findings consisted of postmortem shark bites in the melon and in the dorsal and ventral abdominal regions. The stomach contained little ingesta indicating the animal had been anorectic for some time prior to death. The thorax was filled with a dark red fluid without blood clots. The lungs, trachea, and primary bronchi were congested and contained frothy fluid. The pulmonary lymph nodes were enlarged, and the spleen was smaller than normal for this species. Small, white to gray necrotic foci were observed in sections of the spleen. The liver was autolytic and congested. The kidneys were congested, and numerous adult parasites (Crassicauda spp.) were found within the ureters. Cetobacterium ceti and Clostridium sordelli spp. (both non-pathogenic bacteria) grew from routine aerobic bacterial cultures of brain, lung and spleen.

Microscopically, small, superficial dermal vessels were congested. Lung parenchyma was diffusely congested with areas of alveolar edema and atelectasia. No cardiac lesions were observed. The lymph nodes and spleen had severe, diffuse, coagulative necrosis and fibrinonecrotic vasculitis with prominent thrombi (Figs. 1 \& 2). A large number of monocytic cells in spleen and lymph nodes had intranuclear inclusion bodies consistent with those of herpesviral or adenoviral infection (Fig. 3). The kidneys showed a chronic, parasitic, granulomatous nephritis, and in the liver, hepatocytes were atrophic and contained grey/brown, intracytoplasmatic lipofuscin pigment. Small fibrin thrombi were observed in the hepatic sinusoids. Submucosal and serosal vessels of the stomach were congested. Of the 4 samples processed, no fat emboli were seen. Although tissues were moderately autolytic, no lesions of gas embolism were observed. The histopathologic diagnosis was a systemic, widespread, necrotizing lymphadenitis and splenitis with acute necrotizing vasculitis and thrombosis.

Ultrastructurally, many, non-encapsulated, $100 \mathrm{~nm}$ herpes virions were observed in nuclei of monocytes

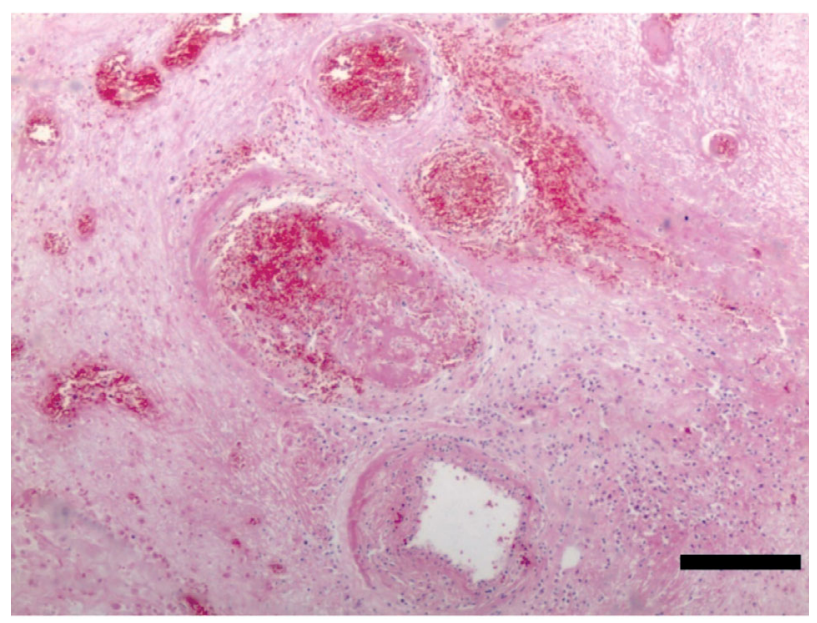

Fig. 1. Ziphius cavirostris. Pulmonary lymph node. Vessels have vasculitis associated with congestion and thrombosis. Hematoxylin \& eosin. Scale bar $=200 \mu \mathrm{m}$ 


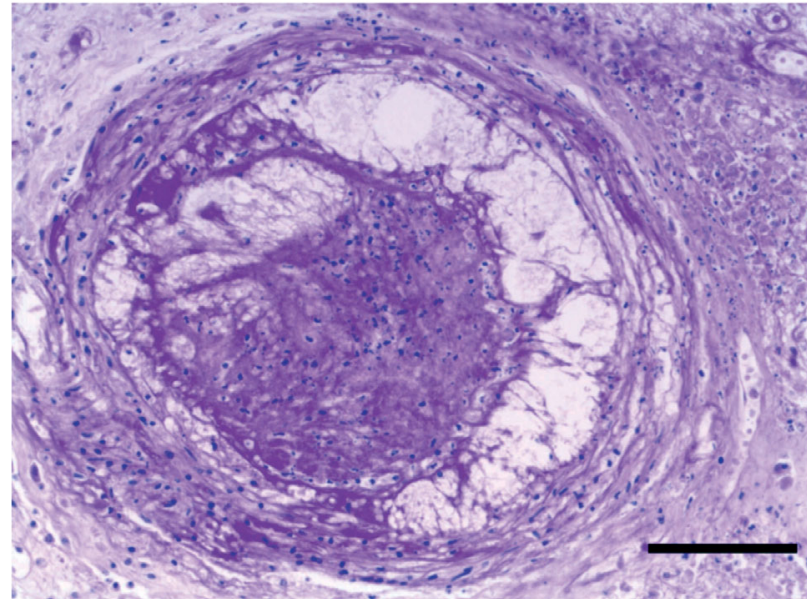

Fig. 2. Ziphius cavirostris. Mesenteric lymph node. Necrotizing vasculitis with a thrombus occluding the lumen. Periodic acid-Schiff stain. Scale bar $=100 \mu \mathrm{m}$

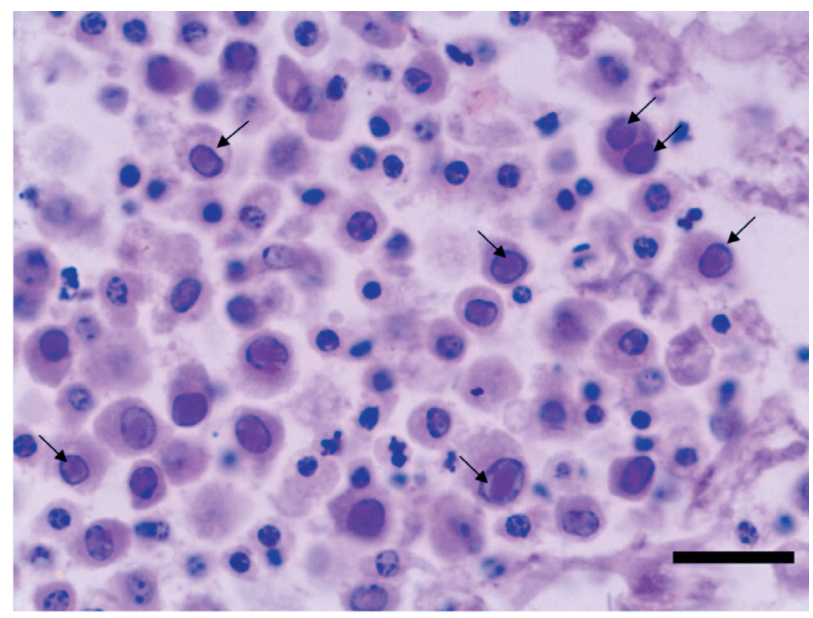

Fig. 3. Ziphius cavirostris. Mesenteric lymph node. Monocytes contain intranuclear inclusion bodies (arrows). Periodic acid-Schiff stain. Scale bar $=20 \mu \mathrm{m}$

from spleen and one abdominal lymph node (Fig. 4) and PCR testing detected Herpesvirus-specific bands in lung and spleen. Results of PCR showed a $198 \mathrm{bp}$ band. Sequencing and further comparison with GenBank records showed a novel sequence highly related to cetacean alpha herpesvirus. The homology to their closest sequences in the Genbank (AF196646 and AY949832) was $84.2 \%$. The sequence of the isolate obtained in this study was classified within the cetacean alphaherpesviruses group, and submitted to GenBank (Accession Number GU066291) (Fig. 5). It was concluded that this beaked whale had a severe, systemic herpesviral infection manifested most prominently in the lymphoid system.

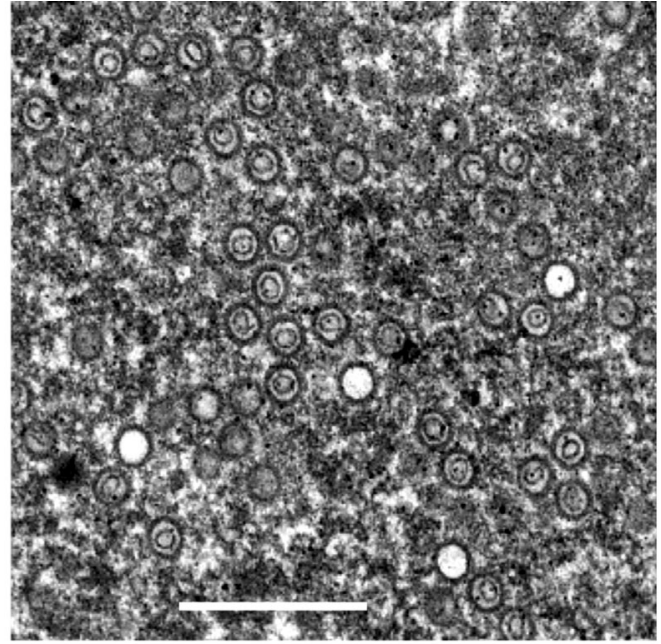

Fig. 4. Ziphius cavirostris. Many virions are observed intranuclearly in the monocytes of the mesenteric lymph node by electron microscopy. Scale bar $=500 \mathrm{~nm}$

Very few data are available about herpesviral systemic infections in cetaceans; one case of encephalitis in a harbour porpoise has been reported (Kennedy et al. 1992). Unfortunately, no brain was tested in the present study. In addition, 2 cases of generalized systemic herpesviral infections in bottlenose dolphins (Blanchard et al. 2001) have been described, and 2 novel sequences from herpesviral polymerase genes were detected. Main pathological findings were observed in the lymphoid system, heart, skin and adrenal glands. These sequences showed a close homology with those described in other bottlenose dolphins with skin diseases (Smolarek-Benson et al. 2006) and therefore they may be considered as the same viral species. In the present study, the PCR results showed a novel sequence classified within the cetacean alphaherpesviruses group.

Few cases involving stranded beaked whales have been published with detailed pathologic findings. This case report documents an infectious disease affecting these poorly known whale species, and records the first case of an alphaherpesvirus affecting the lymphoid system in beaked whales. The virus showed a marked tropism towards the lymphoid system, infecting mainly monocytes which would be the key cell in the pathogenesis of the necrosis observed in the lymph nodes and spleen, as well as the acute necrotizing vasculitis and thrombosis, despite the fact that no herpesviral inclusion bodies or virions were observed in vascular endothelial cells, either histologically or ultrastructurally.

This is the first report of a cetacean alphaherpesvirus infection causing a severe lymphoid necrosis in a stranded beaked whale (Ziphius cavirostris). 

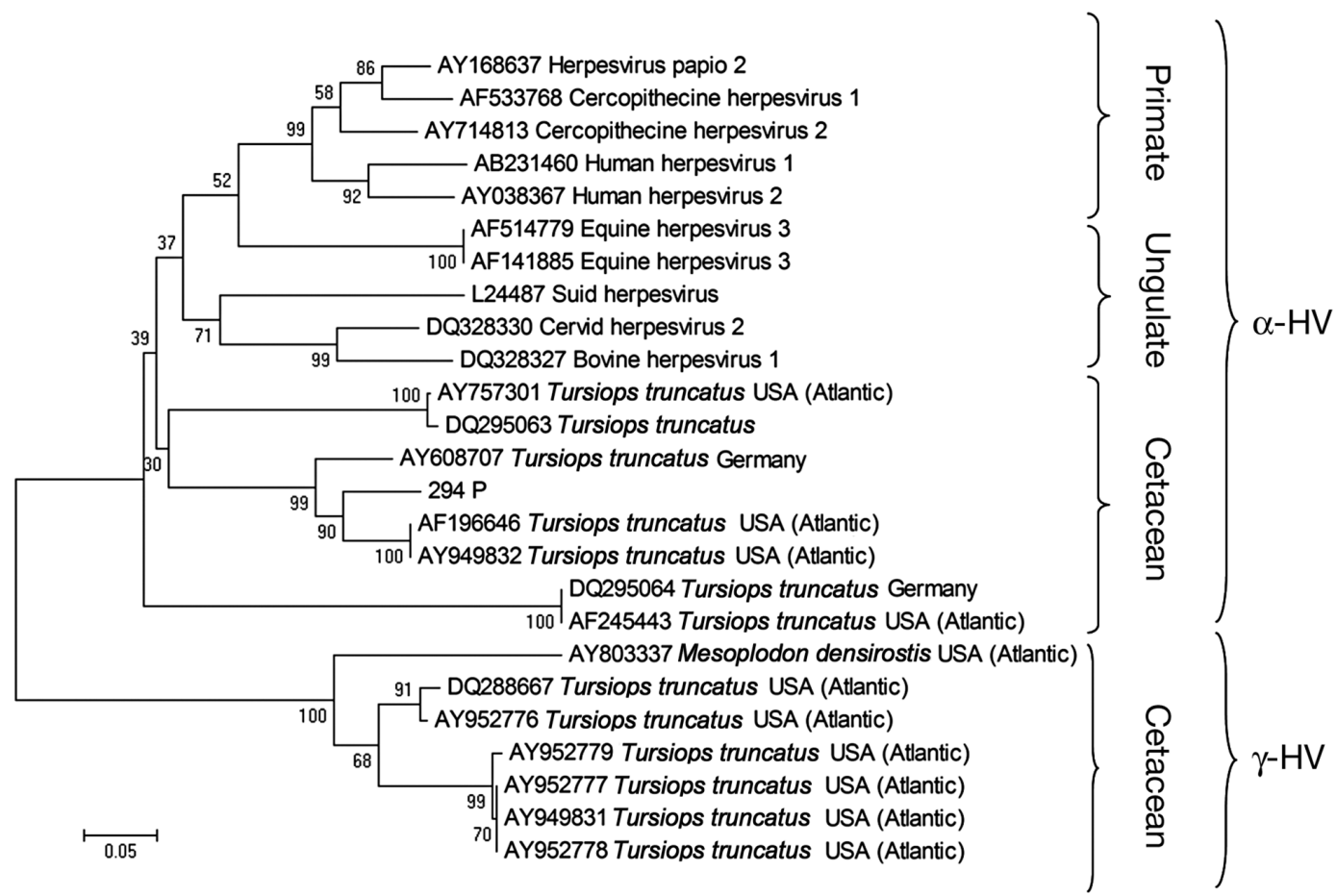

Fig. 5. Neighbor-joining phylogram of 25 selected sequences from cetacean alpha- and gammaherpesvirus (HV) and other phylogenetically related alphaherpesviruses. Either the virus name or the host species is given alongside each GenBank Accession Number. The isolate from the present study (294P, GenBank Accession Number GU066291) showed greatest homology (84.2\%) with Genbank sequences AF196646 and AY949832

Acknowledgements. We thank the Dirección General del Medio Natural del Gobierno de Canarias, Ministerio de Ciencia e Innovación (Project CGL 2009/12663), Ministerio de Medio Ambiente, Rural y Marino and Agencia Canaria de Investigación (C200801000288) for financial support of the present work. We thank Prof. J. Edwards for corrections and comments and B. Muñoz for technical assistance.

\section{LITERATURE CITED}

Arbelo M (2007) Pathology and causes of deaths of stranded cetaceans in the Canary Islands (1999-2005). PhD thesis, University of Las Palmas de Gran Canaria (in Spanish with English abstract)

Baker JR (1992) Skin disease in wild cetaceans from British waters. Aquat Mamm 18:27-32

Blanchard TW, Santiago NT, Lipscomb TP, Garber RL, McFee WE, Knowles S (2001) Two novel alphaherpesviruses associated with fatal disseminated infections in Atlantic bottlenose dolphins. J Wildl Dis 37:297-305

Esperón F, Fernández A, Sánchez-Vizcaíno JM (2008) Herpes simplex-like infection in a bottlenose dolphin stranded in the Canary Islands. Dis Aquat Org 81:73-76

Fernández A (2003) Pathology of beaked whales mass stranded during the naval military maneuvers near the Canary Islands. Proc Workshop Active Sonar and Cetaceans. Eur Cetacean Soc Newsl 42: 37-40

Fernández A, Edwards JF, Rodríguez F, Espinosa A and others (2005) Gas and fat embolic syndrome involving a mass stranding of beaked whales (family Ziphiidae) exposed to anthropogenic sonar signals. Vet Pathol 42:446-457

Hargis AM, Ginn PEJ, Mansell EKL, Garber RL (1999) Ulcerative facial and nasal dermatitis and stomatitis in cats

Editorial responsibility: Michael Moore,

Woods Hole, Massachusetts, USA associated with feline herpesvirus 1 . Vet Dermatol 10: $267-274$

Kennedy S, Lindstedt IJ, McAliskey MM, McConnell SA, McCullough SJ (1992) Herpesviral encephalitis in a harbor porpoise (Phocoena phocoena). J Zoo Wildl Med 23: 374-379

Manire CA, Smolarek KA, Romero CH, Kinsel MJ, Clauss TM, Byrd L (2006) Proliferative dermatitis associated with a novel alphaherpesvirus in an Atlantic bottlenose dolphin (Tursiops truncatus). J Zoo Wildl Med 37:174-181

Martín V, Tejedor M (2009) Summary results of 20 years of beaked whale strandings in the Canary Islands. Eur Cetacean Soc Spec Publ 51:26-28

Martineau D, Lagacé A, Béland P, Higgens R, Armstrong D, Shugart LR (1988) Pathology of stranded beluga whales (Delphinapterus leucas) from the St. Lawrence Estuary, Québec. Canada. J Comp Pathol 98:287-311

Saliki JT, Cooper EJ, Rotstein DS, Caseltine SL and others (2006) A novel gammaherpesvirus associated with genital lesions in a Blainville's beaked whale (Mesoplodon densirostris). J Wildl Dis 42:142-148

Smolarek-Benson KA, Manire CA, Ewing RY, Saliki JT, Townsend FI, Ehlers B, Romero CH (2006) Identification of novel alpha- and gammaherpesviruses from cutaneous and mucosal lesions of dolphins and whales. J Virol Methods 136:261-266

- Van Bressem MF, Van Waerebeek K, Garcia-Godos A, Dekegel D, Pastoret PP (1994) Herpes-like virus in husky dolphins, Lagenorhynchus obscurus, from coastal Peru. Mar Mamm Sci 10:354-359

> VanDevanter DR, Warrener P, Bennett L, Schultz ER, Coulter S, Garber RL, Rose TM (1996) Detection and analysis of diverse herpesviral species by consensus PCR. J Clin Microbiol 34:1666-1671

Submitted: July 20, 2009; Accepted: January 27, 2010

Proofs received from author(s): March 31, 2010 